\title{
SEIS TESIS PARA DESMITIFICAR EL NEXO ENTRE MIGRACIÓN Y DESARROLLO
}

\author{
RAÚL DELGADO WISE* \\ HUMBERTO MÁRQUEZ COVARRUBIAS** \\ HÉCTOR RODRÍGUEZ RAMÍREZ ${ }^{* * *}$
}

RESUMEN: La concepción dominante sobre el nexo entre migración y desarrollo supone que la migración internacional promueve el desarrollo en los lugares y países de origen. Esta postura carece de sustento teórico y empírico, puesto que, entre otras limitaciones, ignora las causas del éxodo de millones de trabajadores del mundo que se han visto forzados a buscar el sustento familiar en lo países desarrollados; hace tabla rasa de las contribuciones de los inmigrantes al crecimiento de las economías receptoras, y encubre las múltiples transferencias y costos, materiales y humanos, que la migración significa para los países emisores, con el agravante de que estas pérdidas no son compensadas por el flujo de remesas. Este artículo propone la construcción de una visión integral del fenómeno a partir de seis tesis que, a la vez que tienen el cometido de desmitificar la visión convencional, develan aspectos clave del proceso de reestructuración capitalista neoliberal impulsado en las últimas tres décadas y media a nivel mundial. En esta perspectiva, el caso México-Estados Unidos resulta paradigmático para demostrar el cúmulo de pérdidas socioeconómicas para los países exportadores de fuerza de trabajo y los enormes beneficios para los países importadores de trabajadores.

PALABRAS CLAVE: Desarrollo desigual, migración forzada, reestructuración capitalista, transferencia de excedentes, remesas.

ABSTRACT: The reigning assumption in migration and development studies is that international migration promotes development in places and countries of origin. But this idea lacks a theoretical and empirical basis: it ignores the root causes underlying the exodus of millions of poor workers forced to struggle for their survival in the developed nations; it discards the contributions made by migrants to the economy of the receiving countries, and obscures the many transferences and costs migration represents for sending countries -loses that are not compensated by remittance flow. This article proposes the construction of a comprehensive approach to the phenomenon through six theses that analyze key aspects of the global capitalist restructuring process in practice during the past three decades. The Mexico-United States case is used as a paradigmatic example of the socioeconomic losses incurred by workforce-exporting nations and the enormous benefits reaped by importing countries.

KEYWORDS: Unequal development, forced migration, capitalist restructuring, surplus transference, remittances.

\footnotetext{
* Director de la Unidad Académica en Estudios del Desarrollo de la Universidad Autónoma de Zacatecas y Presidente de la Red Internacional de Migración y Desarrollo. Correo electrónico: rdwise@estudiosdeldesarrollo.net.

** Profesor-investigador de la Unidad Académica en Estudios del Desarrollo. Correo electrónico: hmarquez@estudiosdeldesarrollo.net.

**** Director del Área de Economía y Gobierno de la Escuela de Graduados en Administración Pública y Política Pública del Itesm, Campus Monterrey. Correo electrónico: hrr@itesm.mx.
} 


\section{INTRODUCCIÓN}

inicios de la década de los setenta, una de las principales barreras para
la acumulación de capital estaba representada por la cuestión laboral
(Harvey, 2003). Entonces, el gran desafío, particularmente para las
grandes corporaciones capitalistas, consistía en abaratar y doblegar a la fuerza de trabajo. La respuesta estratégica se encausó por tres vías complementarias: 1) el desplazamiento de capitales hacia regiones periféricas con abundante mano de obra barata; 2) el impulso del cambio tecnológico, sobre todo aquel asociado con la configuración de cadenas globales de producción (Gereffi, 2001), ${ }^{1}$ y 3) la atracción de inmigración a los países centrales para aprovechar la sobrepoblación mundial como fuente de trabajo barato.

En el curso de las últimas tres décadas y media, los países centrales han desplegado una compleja estrategia de reestructuración del sistema capitalista mundial que atiende a los intereses de los grandes capitales transnacionales. Entre los elementos esenciales de dicha estrategia destacan la internacionalización de la producción, las finanzas y el comercio bajo la batuta de las grandes corporaciones transnacionales; ${ }^{2}$ la aplicación de políticas neoliberales de ajuste estructural con el propósito de reinsertar a la periferia, bajo pautas asimétricas y subordinadas, en la nueva dinámica de acumulación mundial; la inducción de los procesos de innovación científico-tecnológica en proyectos de corto plazo según lo requiriese la internacionalización del capital y la expansión desbordante del capital financiero, el cual, dicho sea de paso, observa una dinámica muy superior al movimiento de la llamada economía real, pero que acelera los procesos de concentración y centralización de capital y distorsiona sobremanera el funcionamiento del sistema capitalista en su conjunto. El despliegue de estos procesos ha estado apuntalado por la militarización de las relaciones internacionales y la mercantilización de un amplio espectro de recursos naturales.

El nuevo andamiaje de la economía política mundial toma la forma de una expansión capitalista extensiva y contradictoria fincada en la incorporación masiva de fuerza de trabajo barata ${ }^{3}$ a modalidades extremas de explotación laboral, donde la migración y, en sentido más amplio, la exportación de fuerza de trabajo, se han convertido -como detallaremos más adelante- en las piezas clave. Los resultados que arroja esta configuración capitalista son contrastantes: una descomunal concentración de capital; un agudo crecimiento de las asimetrías entre países, particularmente en el horizonte Norte-Sur, y un incremento sin precedentes de las des-

1 Cabe acotar que si bien retomamos el concepto de cadenas globales de producciones acuñado por Gereffi, no compartimos con él su visión optimista sobre la globalización y el papel de los diferentes eslabones de las cadenas en la promoción del desarrollo de los países integrados a estas cadenas.

2 A tal grado se ha expandido este proceso que en las cadenas globales de producción participan en la actualidad alrededor de 55 millones de trabajadores (Robinson, 2008).

${ }^{3}$ Con el ingreso de los países ex socialistas y de grandes naciones como China e India, la fuerza laboral a disposición del capital se incrementó de 1.46 a 3 mil millones de personas (Robinson, 2008). 
igualdades sociales. Más aún, en los últimos dos años irrumpe una profunda crisis sistémica con cariz multidimensional, que no sólo da muestras de profundidad y larga duración, sino que también cuestiona seriamente la estrategia de reestructuración capitalista implantada desde la primera mitad de la década de los setenta.

Haciendo abstracción del contexto de reestructuración económica y precarización laboral en el que se inscribe la dinámica migratoria contemporánea, el debate dominante sobre el nexo entre migración y desarrollo parte de una creencia, elevada al estatuto de mito o mantra: la migración contribuye al desarrollo de los lugares y países de origen. Entre los supuestos que alimentan esta visión, destaca: 1) la migración es fuente del desarrollo para el país expulsor, donde los migrantes son el agente y las remesas, el motor o palanca; 2) la migración adquiere una dinámica propia, autogenerada, que no reconoce causas estructurales; 3) la migración representa una carga y las remesas una fuga de recursos para el país receptor; 4) los migrantes son responsables del deterioro laboral y de la calidad de vida en la sociedad receptora, y 5) la migración deviene en una estrategia de combate a la pobreza que reviste de poder económico a los pobres.

Esta concepción, aparte de unilateral y sesgada, es un contrasentido, porque son precisamente las condiciones de subdesarrollo, y en particular los procesos de reestructuración neoliberal, que profundizan el subdesarrollo y acrecientan las asimetrías Norte-Sur, los que precipitan la expulsión laboral y nutren la nueva dinámica migratoria. Desde una perspectiva crítica, es posible advertir que esta concepción deviene en una distorsión de la realidad, pues tiene el cometido de crear la ilusión de que los migrantes y las remesas (concebidas como un caudal inagotable de recursos monetarios) pueden y deben contribuir al desarrollo de los países de origen.

Para desmitificar esa visión ideológica, es menester evidenciar las relaciones cruciales que oculta: las causas estructurales de las migraciones, la contribución de los migrantes a la economía y sociedad receptora y las formas de transferencia económica, social y poblacional de los países emisores hacia los receptores que implica la migración internacional. A nivel de las causas es imprescindible advertir la estrategia de expansión capitalista basada en el abaratamiento, precarización y exportación de fuerza de trabajo de distintos ámbitos de la periferia, así como de los países de ex socialistas. Es decir, se trata de un movimiento simultáneo de desarticulación y exclusión económica en la periferia y, al mismo tiempo, de reinserción asimétrica y subordinada a la órbita de los países centrales.

Para desentrañar empíricamente la relación entre desarrollo y migración recurrimos al caso del sistema migratorio conformado entre México y Estados Unidos, por ser altamente representativo del fenómeno que analizamos. Por un lado, Estados Unidos además de figurar como la principal potencia capitalista y encabezar la referida estrategia de reestructuración, es el principal receptor de migrantes y emisor de remesas del mundo. Por otro lado, México despunta como 
un país relativamente industrializado de la periferia que adopta, a rajatabla, los programas de ajuste estructural y se convierte en el principal emisor de migrantes y segundo receptor de remesas del orbe. Entre ambos países se teje, asimismo, una modalidad de integración regional auspiciada por el Tratado de Libre Comercio de América del Norte (TLCAN), que atiende primordialmente a los intereses estratégicos de las grandes corporaciones transnacionales de base estadounidense.

Partiendo de estas grandes premisas, nuestro argumento se articula mediante la enunciación de seis tesis sobre las causas de la migración, las contribuciones de los migrantes al crecimiento económico de los países receptores, la transferencia de recursos del país de origen al de destino que se produce a través del proceso migratorio y la insuficiencia de las remesas como recurso para el desarrollo del país emisor.

\section{DESARROLLO DESIGUAL Y EXPORTACIÓN DE FUERZA DE TRABAJO}

El capitalismo contemporáneo resulta pobremente dibujado bajo la aséptica noción de globalización, porque se remite a describir el flujo de capitales, información, tecnologías y personas por el ancho mundo del mercado, amén de que termina siendo una ideología que considera a la sociedad contemporánea como una cristalización de la historia, un mundo sin alternativas. Más allá de esa visión insustentable, que descansa en una fe ciega en el libre mercado como vía para alcanzar una sociedad global justa y equitativa, conviene advertir que las últimas tres décadas y media han estado dominadas por una estrategia de expansión capitalista con saldos desastrosos en términos de desarrollo y justicia social. La noción de desarrollo desigual resulta particularmente útil para describir y analizar esta situación, por cuanto hace referencia al proceso histórico de polarización económica, social y política entre regiones, países y clases derivado de las dinámicas de la acumulación capitalista, la división internacional del trabajo y los conflictos de clase en diversos planos y niveles.

En esta perspectiva, a fin de comprender el proceso de desarrollo desigual que caracteriza al capitalismo contemporáneo y diseccionar los factores que explican el nuevo perfil, dinámica y funcionalidad de las migraciones internacionales, resulta fundamental poner de relieve que, en el contexto actual, a la periferia le ha correspondido desempeñar un nuevo y decisivo papel como proveedora de fuerza de trabajo barata y recursos naturales para el mundo desarrollado. Los programas neoliberales de ajuste estructural han tenido, precisamente, ese cometido al generar un triple movimiento en las economías periféricas (Delgado Wise y Márquez, 2007): a) desmantelamiento y rearticulación de sus estructuras económicas; b) estrechamiento del mercado laboral y generación de una profusa sobrepoblación, y c) desbordamiento de la migración laboral. Este triple movimiento define los contornos de una nueva división internacional del trabajo caracterizada por: 
1. La reinserción de los países de la periferia al sistema capitalista mundial en calidad de apéndices de las cadenas globales de producción, comercio y finanzas. Al amparo de la estrategia de reestructuración capitalista mundial y bajo las presiones del Fondo Monetario Internacional (FMI), el Banco Mundial (BM) y la Organización Mundial del Comercio (OMC), se implanta una serie de políticas de corte neoliberal fincadas en la triada: apertura, desregulación y privatización. Estas políticas son ejecutadas a través de los llamados programas de ajuste estructural que, a través del triple movimiento referido, crean condiciones propicias para la reinserción de los países periféricos -incluyendo algunos países del ex bloque socialista- a los procesos de internacionalización del capital comandados por las grandes corporaciones transnacionales, y

2. La exportación de fuerza de trabajo barata. La forma que asume la reinserción de la periferia al sistema capitalista mundial da paso a una nueva división internacional del trabajo, donde la venta al exterior de la principal mercancía para el crecimiento y desarrollo económicos, la fuerza de trabajo, se convierte en un elemento central del intercambio entre centro y periferia. Esta exportación se produce por dos vías interrelacionadas: por un lado, la exportación indirecta o disembodied de fuerza de trabajo empleada en las plantas de ensamble de los países periféricos (mediante operaciones de maquila o subcontratación), en tanto eslabones de las cadenas globales de producción, y, por el otro lado, la migración laboral o exportación directa de fuerza de trabajo. En el primer caso, las grandes corporaciones transnacionales logran acceder a fuerza de trabajo de regiones y países periféricos mediante el desplazamiento de una parte del proceso productivo global, sin que ello dé lugar a encadenamientos productivos hacia delante o hacia atrás con el resto de la estructura productiva del país donde se instalan. Se trata de verdaderos enclaves que generan en los países periféricos la apariencia de avances en su plataforma de exportación hacia bienes manufacturados e incluso commodities, pero que en realidad significan una regresión, puesto que lo único que aportan al proceso de acumulación son salarios bajos y, en el mejor de los casos, un limitado impacto multiplicador vía consumo. Bajo esta modalidad de exportación, el país periférico transfiere las ganancias netas al exterior -muchas veces a través de operaciones intrafirma-, exentas en la mayoría de los casos del pago de impuestos y libres de toda responsabilidad en cuanto a posibles daños ambientales. En el segundo caso, i.e. la exportación directa de fuerza de trabajo, se atiende a la demanda de trabajo barato en los propios territorios del capitalismo central con el propósito no sólo de satisfacer una demanda que el país receptor no puede cubrir, sino también de, y ante todo, abaratar costos laborales.

Este ámbito de la nueva división internacional del trabajo, que podríamos caracterizar como exportación de fuerza de trabajo, se monta sobre la base de un ataque sistemático a las condiciones de vida y trabajo de la mayoría de la población y entraña una creciente desvalorización y abaratamiento de los costos de la fuerza laboral, incluso muchas veces por debajo de su valor, es decir, bajo condiciones de superexplotación. En este contexto hay países, como México (Delgado 
Wise y Márquez, 2007) y la mayoría de las principales naciones emisoras de migrantes, que se especializan en la exportación de fuerza de trabajo barata y que, en consecuencia, experimentan significativas regresiones en sus dinámicas de desarrollo y ocupan una posición extremadamente desfavorable y desventajosa en el (des)concierto capitalista contemporáneo.

Asimismo, la nueva arquitectura global incluye -como apuntamos en el apartado anterior- el desbordamiento del capital financiero-especulativo y la devastación ambiental, ${ }^{4}$ lo que agrava aún más las contradicciones del sistema y acentúa sus rasgos excluyentes. Bajo estas circunstancias, el panorama del desarrollo desigual se encuentra teñido por crecientes y aberrantes desigualdades sociales, el aumento sin precedentes de las asimetrías entre países, así como el desbordamiento de la migración de la periferia al centro. Todo lo cual se inscribe, a su vez, en una creciente transnacionalización, diferenciación y precarización de los mercados laborales que moldea los flujos poblacionales y los hace más complejos. De ahí la necesidad de repensar teórica, conceptual y empíricamente las migraciones internacionales y, más específicamente, la naturaleza del vínculo entre desarrollo y migración.

\section{LA NUEVA MOVILIDAD POBLACIONAL: MIGRACIÓN FORZADA}

De manera consustancial al desarrollo desigual, la migración internacional toma la configuración, ya no de una movilidad poblacional indiferenciada, sin causales estructurales, sino con mayor propiedad de una migración forzada..$^{5}$ Desde esta

${ }^{4}$ Bajo el precepto de un mercado abarcador o totalizante, se han incorporado a la lógica del mercado inconmensurables recursos naturales de la biosfera, litosfera y estratosfera. Pero como la consigna es la obtención del mayor margen de ganancias en el menor tiempo posible, no se tiene el menor escrúpulo en agotar estos recursos naturales, sin importar por tanto los efectos contaminantes, destructores y extinguidores. Distintos científicos e instituciones han llamado la atención sobre la emergencia de fenómenos graves como el calentamiento global, el cambio climático y la pérdida de biodiversidad, pero también del trastrocamiento del metabolismo social, es decir, de la interacción necesaria entre la humanidad y el medio ambiente como condición necesaria para la reproducción de la vida humana en el planeta.

${ }_{5}$ De manera convencional, los organismos internacionales se refieren a la migración forzada para aquellos casos de movilidad poblacional generada por 1) conflictos sociales, políticos, religiosos o comunitarios; 2) desastres naturales, y 3) violencia armada como guerras o guerrillas. De este modo, los migrantes forzados pueden ser asilados, desplazados o refugiados. Desde esta óptica, se dejan de lado las causas estructurales de este tipo de migraciones, esto es, el grueso de los asilados, refugiados y desplazados procede de países devastados por la violencia, la naturaleza y el conflicto, cuya matriz causal intrínseca se localiza en la profundización del subdesarrollo. La mera consideración de la defensa de los derechos humanos de los migrantes, siendo importante, no atiende las causas de fondo. Esta visión también omite las migraciones laborales catapultadas por las políticas neoliberales, la inserción a la economía mundial y en general las diversas expresiones del desarrollo desigual. Por si fuera poco, conviene advertir que el concepto de migración forzada ya se utilizaba en el siglo XIX, desde la crítica de la economía política propuesta por Marx, para referirse a la migración laboral ocasionada por las contradicciones socioeconómicas del desarrollo capitalista y, en particular, al caso de la migración irlandesa. 
perspectiva, la migración forzada se refiere a procesos de expulsión de población redundante o precarizada emanada de los países periféricos hacia los países centrales que demandan contingentes laborales para abaratar sus procesos productivos. Las condiciones de desempleo estructural, desmantelamiento del mercado interno, destrucción de cadenas productivas, junto al incremento de la pobreza, marginación e inseguridad, generan un caldo de cultivo que amenaza en los lugares de origen las condiciones materiales y subjetivas para la subsistencia familiar y el arraigo de las personas. Como correlato, la demanda incesante de fuerza de trabajo altamente calificada, calificada o poco calificada por el capital asentado en países centrales actúa como motor de los flujos migratorios. No obstante, las condiciones prevalecientes, en la mayoría de los casos, de criminalización migratoria, precarización laboral, exclusión social y discriminación ponen en riesgo permanente la vida de los inmigrantes. En el ínter, el cruce migratorio por las diversas fronteras está acompañado de múltiples peligros y riesgos, los cuales pueden ser parcialmente paliados por redes sociales. En todo caso, la migración forzada es una expresión de la vulnerabilidad de la vida humana bajo la estrategia neoliberal, donde las personas son reducidas a su estatuto de mercancía humana sometida a condiciones de explotación extrema.

\section{Tesis 1. La nueva movilidad poblacional en el contexto de la} reestructuración capitalista asume la modalidad de migración forzada

Para analizar la economía mexicana, en tanto caso prototípico del modelo de exportación de fuerza de trabajo y su correlato, la migración forzada, es menester considerar el contexto de integración regional más amplio en el que se inscribe. Este contexto de integración, signado por el TLCAN, se caracteriza por el desmantelamiento del proceso de industrialización basado en la sustitución de importaciones seguido por el país desde la posguerra y el vuelco de la economía mexicana hacia la producción para la exportación dirigida principalmente al mercado estadounidense. El componente principal de las exportaciones lo constituyen dos eslabones importantes de las cadenas globales de producción: la maquila y la maquila encubierta, ${ }^{6}$ que representan el $90 \%$ de las exportaciones manufactureras, aunque entre el 70 y $90 \%$ de sus insumos son importados. Bajo esa tónica, lo que en realidad se exporta, bajo el disfraz de manufacturas, es fuerza de trabajo sin que ésta salga del país.

La reorientación de la economía mexicana hacia el mercado internacional ha traído consigo una significativa contracción y precarización del mercado laboral

\footnotetext{
${ }^{6}$ La maquila encubierta abarca segmentos importantes del sector exportador, como el automotriz, que en las clasificaciones oficiales no se catalogan como maquila, pero que funcionan bajo principios similares con un elevadísimo componente de insumos importados y fungiendo como eslabón de procesos productivos altamente internacionalizados (Delgado Wise y Cypher, 2007).
} 
formal. En efecto, entre 1994 y 2008 el empleo formal, si se toma como referencia los asegurados por el Instituto Mexicano del Seguro Social (IMSS), registró un aumento anual de apenas 489,000 empleos. Esta cifra representa el 30\% del incremento de la Población Económicamente Activa (PEA) en México, lo que significa que el restante $70 \%$ tuvo que refugiarse en el sector informal o emigrar en busca del sustento.

Los movimientos masivos de población que caracterizan a la nueva dinámica migratoria devienen de procesos de expulsión derivados de la estrechez y precariedad del mercado laboral formal y el desbordamiento de la informalidad en condiciones de explotación extrema, que obligan a vastos sectores a emigrar. No obstante, las restricciones a la movilidad de la fuerza de trabajo migrante (i.e. criminalización), la desvalorizan y someten a condiciones de elevada vulnerabilidad, exclusión social, precariedad y explotación.

México cuenta con una larga tradición migratoria hacia Estados Unidos de más de un siglo. Sin embargo, no se trata de un fenómeno lineal. En el curso de este peregrinaje se han producido importantes transformaciones cuantitativas y cualitativas en la dinámica migratoria estrechamente relacionadas a los cambios en el modelo de desarrollo o de acumulación de capital en el país y a las diferentes modalidades de inserción o integración regional con la economía de Estados Unidos.

En el contexto actual, la emigración ha crecido de manera explosiva. Entre 1990 y 2008 la población nacida en México residente en Estados Unidos se incrementó de 5.2 a 11.6 millones. El número de residentes de origen mexicano en Estados Unidos se estima en 29.7 millones. De acuerdo con estimaciones de la Current Population Survey (CPS), entre 2000 y 2008, un promedio anual de 475 mil personas emigró a Estados Unidos (alrededor de 50\% indocumentada). Aunado a lo anterior, se registra una expansión territorial del fenómeno en México y Estados Unidos. En México, el fenómeno territorialmente estaba localizado en el centro-occidente, pero ahora adquiere una cobertura nacional, al incorporar nuevas zonas rurales y urbanas $y$, particularmente, metropolitanas, producto del desmantelamiento de cadenas productivas y precariedad laboral. Según estimaciones del Consejo Nacional de Población (Conapo) basadas en la American Community Survey (ACS), en Estados Unidos la inmigración mexicana se ha extendido a toda la geografía de ese país, al grado de convertir a los mexicanos en el primer grupo de inmigrantes en 31 de los 50 estados de ese país.

La transformación del patrón migratorio, de predominantemente circular a establecido, así como su carácter compulsivo, han consolidado un fenómeno sintomático: el despoblamiento. Entre 2000 y 2005, 50\% de los municipios registraron tasas negativas de crecimiento poblacional (Conapo, 2008). En el contexto de la nueva dinámica migratoria a nivel mundial, México se ha convertido en un importante país de tránsito, principalmente de Centroamérica. Además, se registran encadenamientos de migración interna, de tránsito e internacional que proyectan dinámicas de estratificación hacia abajo asociadas a los procesos de precarización laboral y exclusión social. 
Más aún, acontece una suerte de selectividad creciente del fenómeno migratorio en términos educativos: más profesionistas están emigrando. En 1994, 71.2\% de los migrantes mexicanos disponían de calificación baja; $25.2 \%$, calificación media; 3.6\%, calificación alta. Para 2008, el 61.4\% de los migrantes mexicanos poseía baja calificación; 33.7\%, calificación media; 4.7\%, calificación alta. Visto desde las tasas de crecimiento promedio anual, entre 1994 y 2008 la migración de baja calificación creció 4.9\%; la semicalificada, 10\%, y calificada, 11.7\% (CPS, 1994, 2008). Vale la pena recalcar que datos de la ACs (2008) revelan que en 2007 radicaban 14,389 migrantes mexicanos con grado de doctor en Estados Unidos, mientras que en México se estima en alrededor de 28,390 (ENOE, 2007), de los cuales 13,485 pertenecen al Sistema Nacional de Investigadores (SNI). El papel de estos doctores es, sin embargo, diferente. En Estados Unidos una parte importante se incrusta en procesos de innovación. En cambio, en México, la mayoría está inmersa en el sector educativo.

Otro movimiento interesante es la mayor participación en el sector industrial. De 1994 a 2008, el número de migrantes mexicanos ocupados en el sector industrial creció de 1.3 millones a 2.8 millones. En último año, 38\% de los mexicanos estaban ocupados en la industria, mientras que en Estados Unidos 19.3\%, en promedio, participan en el sector.

Pero más allá de su expresión cuantitativa y cualitativa, la migración forzada significa una pérdida invaluable de población para México, cuando menos en tres sentidos:

1. El traspaso del llamado bono demográfico. Se transfiere la población joven que se suma al mercado laboral, pero que no encuentra ocupación o remuneración suficiente. Este es un signo de la pérdida de soberanía laboral del país emisor (Márquez, 2008). Para el país receptor, significa un recurso fresco para mantener el ciclo de reproducción demográfica acorde a las necesidades laborales.

2. La pérdida del recurso central para la acumulación nacional: la fuerza laboral, la fuente principal para la creación de riqueza. De este modo, la migración, más que un dato demográfico en ascenso, es un signo de la profundización del subdesarrollo y de las dificultades para emprender procesos significativos de transformación social.

3. Exclusión económica en la periferia e inclusión laboral precarizada con segregación social en el centro. La conjunción de mecanismos de expulsión de población convertida en redundante por la reestructuración neoliberal de las regiones periféricas que tiene su correlato en los mecanismos de incorporación al mercado laboral de los países centrales en condiciones de elevada vulnerabilidad y precarización, como se verá con mayor detalle en la tesis 2 .

\section{CONTRIBUCIONES DE LOS MIGRANTES AL CRECIMIENTO ECONÓMICO DEL PAÍS RECEPTOR}

Desde la visión que sobre las migraciones internacionales se ha erigido en las últimas dos décadas, surge el argumento de que el diferencial salarial y la emergencia 
de una suerte de cultura de la migración potencializa el flujo migratorio, y de que en el país receptor los migrantes a) presionan al mercado de trabajo y disputan fuentes de empleo a los trabajadores nativos; $b$ ) constituyen una carga para el Estado al demandar servicios públicos y sociales, yc) se convierten en una amenaza para la cohesión social por ser portadores de tradiciones y costumbres anacrónicas o simplemente diferentes. Pero más aún, para la mayoría de los analistas, gobiernos y organismos internacionales, el foco de atención ha estado centrado en los supuestos beneficios de las remesas en los lugares y regiones de origen.

Para cambiar esa visión ortodoxa sobre migración y desarrollo, es importante tomar en cuenta el papel que juegan los migrantes en la dinámica de acumulación de capital en la economía receptora. Desde una visión crítica el argumento principal se coloca en las antípodas de la convencionalidad: la contribución más significativa de los migrantes se realiza en el país de destino, no en el país de origen.

\section{Tesis 2. La migración forzada cumple un papel estratégico en el suministro} de fuerza de trabajo barata, flexible y desorganizada para la economía receptora

La estrategia expansiva de acumulación de capital a escala mundial reclama la baratura de la fuerza de trabajo. Las economías de los países periféricos han sido penetradas por el capital central para aprovechar ese recurso abundante, y han sido obligadas a reorientar los ciclos de inversión, producción, comercialización y distribución. En esta tónica, la migración laboral asciende notablemente para alimentar los requerimientos laborales de los países desarrollados.

Al tiempo en que desmantela su modelo de desarrollo basado en la industrialización por sustitución de importaciones e implanta sin cortapisas el modelo neoliberal, México se ha consolidado como uno de los principales proveedores de fuerza de trabajo barata para la economía de Estados Unidos, por vía indirecta (maquilización de la manufactura, agribusiness en el campo, extranjerización de la banca y el comercio) y por vía directa (principal suministrador directo de mano de obra). El rasgo más sobresaliente de la descomposición socioeconómica es la importancia central de la migración forzada. Los datos sobre ocupación, derivados de la CPS, muestran el papel estratégico que cumplen los migrantes en el mercado laboral estadounidense. Entre 1994 y 2008, se crearon en ese país poco más de 23.2 millones de empleos, de los cuales el $46.2 \%$ fueron ocupados por población migrante (véase tabla 1).

En este escenario, los migrantes mexicanos conformaron el principal grupo de población migrante proveedor de mano de obra. En efecto, entre 1994 y 2008, el grupo de mexicanos contribuyó con 3.8 millones de ocupaciones, cifra que representa una tercera parte del empleo ofertado por la población migrante y el 16\% del total del empleo generado en Estados Unidos en dicho periodo, es decir, 1 de cada 6. 
TABLA 1

Población ocupada en Estados Unidos según condición migratoria, 1994-2008

\begin{tabular}{|l|r|r|r|c|}
\hline \multicolumn{1}{|c|}{ OCUPADOS } & \multicolumn{1}{|c|}{1994} & \multicolumn{1}{c|}{2008} & $\begin{array}{c}\text { DIFERENCIA } \\
1994-2008\end{array}$ & $\begin{array}{c}\text { TASA DE CRECIMIENTO } \\
\text { MEDIA ANUAL } \\
1994-2008\end{array}$ \\
\hline Población ocupada & \multicolumn{1}{|c|}{$129^{\prime} 714,943$} & $152^{\prime} 986,375$ & $23^{\prime} 271,432$ & $1.3 \%$ \\
\hline Población ocupada nativa & $116^{\prime} 753,126$ & $129^{\prime} 266,308$ & $12^{\prime} 513,182$ & $0.8 \%$ \\
\hline Población ocupada migrante & $12^{\prime} 961,817$ & $23^{\prime} 720,067$ & $10^{\prime} 758,250$ & $5.9 \%$ \\
\hline Población ocupada migrante no mexicana & $9^{\prime} 323,008$ & $16^{\prime} 226,064$ & $6^{\prime} 903,056$ & $5.3 \%$ \\
\hline Población ocupada migrante mexicana & $3^{\prime} 638,809$ & $7^{\prime} 494,003$ & $3^{\prime} 855,194$ & $7.6 \%$ \\
\hline
\end{tabular}

Fuente: Cálculo propios con base en la Current Population Survey, Suplemento de Marzo, 1994-2008.

En términos relativos resulta aún más evidente el importante papel que cumplen los migrantes, particularmente los mexicanos, en el mercado laboral estadounidense. Destaca el hecho de que la dinámica de empleo de los migrantes mexicanos representa $7.6 \%$ del crecimiento medio anual de las ocupaciones.

La compulsiva migración mexicana hacia Estados Unidos, modulada por la política de integración económica regional, genera efectos diferenciados para ambos países. Para el país receptor, los migrantes contribuyen a nutrir y flexibilizar la oferta de fuerza de trabajo en determinados segmentos del mercado laboral, abaratan costos laborales e incrementan los beneficios para el capital. No se trata simplemente de un proceso regulado por el libre juego de la oferta y demanda de mano de obra, sino, en múltiples sentidos, de una estrategia empresarial deliberada que pretende abaratar costos laborales mediante el reemplazo masivo de trabajadores nativos en determinados segmentos de la economía estadounidense. $\mathrm{Al}$ respecto, cabe señalar que a nivel de la industria manufacturera, acontece un doble proceso de reestructuración laboral y de estrategias corporativas, en donde los migrantes juegan un papel central. Por un lado, se advierte un proceso de sustitución laboral donde la población migrante está cobrando cada vez mayor relevancia. En efecto, los datos contenidos en la tabla 2 revelan la sustitución laboral de migrantes por nativos en la ocupación manufacturera: entre 1994 y 2008, el personal nativo ocupado en la manufactura disminuyó en alrededor de 4.2 millones de personas, en tanto que el número de migrantes ocupados en el sector aumentó en 813 mil, de los cuales poco más de 300 mil (40\%) fueron mexicanos. Por otro lado, para ciertos grupos de migrantes, en particular los migrantes mexicanos que laboran en este sector, se registran empleos con muy bajo nivel salarial. Los datos de la tabla 2 dan cuenta de las muy significativas diferencias salariales entre los nativos y los inmigrantes no mexicanos respecto a los migrantes mexicanos que laboran en la manufactura. Tómese en cuenta que en 2008, el salario promedio anual de un migrante mexicano ocupado en la manufactura es equivalente al salario promedio que 14 años atrás (1994) tenía un nativo ocupado en este sector. 
Los datos anteriores no hacen más que evidenciar que el mercado laboral estadounidense está en proceso de reestructuración y precarización y, en esa dinámica, se inscribe el modelo exportador de fuerza de trabajo mexicana (Delgado Wise y Márquez, 2007).

TABLA 2

Ocupados en la manufactura según condición migratoria, 1994-2008

\begin{tabular}{|l|c|c|}
\hline \multicolumn{1}{|c|}{ OCUPADOS Y SALARIO } & 1994 & 2008 \\
\hline Población total ocupada en la manufactura & $20{ }^{\prime} 340,523$ & $16^{\prime} 868,190$ \\
\hline Salario promedio anual (dólares) & $\$ 25,523$ & $\$ 48,910$ \\
\hline Población nativa ocupada en la manufactura & $18^{\prime} 119,790$ & $13^{\prime} 835,048$ \\
\hline Salario promedio anual (dólares) & $\$ 26,008$ & $\$ 50,361$ \\
\hline Población migrante ocupada en la manufactura & 2 '220,733 & $3^{\prime} 033,142$ \\
\hline Salario promedio anual (dólares) & $\$ 22,299$ & $\$ 42,198$ \\
\hline Población migrante no mexicana ocupada en la manufactura & $1^{\prime} 412,495$ & $1^{\prime} 900,300$ \\
\hline Salario promedio anual (dólares) & $\$ 26,514$ & $\$ 51,572$ \\
\hline Población migrante mexicana ocupada en la manufactura & 808,238 & $1^{\prime} 132,842$ \\
\hline Salario promedio anual (dólares) & $\$ 15,002$ & $\$ 26,360$ \\
\hline & & \\
\hline Diferencia salarial del nativo vs migrante mexicano & $\$ 11,006$ & $\$ 24,001$ \\
\hline Diferencia salarial del migrante no mexicano vs mexicano & $\$ 11,512$ & $\$ 25,212$ \\
\hline$\%$ de población ocupada nativa respecto al total de ocupados en manufactura & $89.1 \%$ & $82.0 \%$ \\
\hline $\begin{array}{l}\text { \% de población ocupada migrante no mexicana respecto al total de ocupados } \\
\text { en manufactura }\end{array}$ & $6.9 \%$ & $11.3 \%$ \\
\hline $\begin{array}{l}\text { \% de población ocupada migrante mexicana respecto al total de ocupados en } \\
\text { manufactura }\end{array}$ & $4.0 \%$ & $6.7 \%$ \\
\hline
\end{tabular}

Fuente: Cálculo propios con base en la Current Population Survey, Suplemento de Marzo, 1994-2008.

En síntesis. En el ámbito laboral, los inmigrantes en general, y los mexicanos en particular, contribuyen a la economía receptora en cinco niveles complementarios:

1. Abaratamiento. La condición de fuerza de trabajo barata, flexible y desorganizada contribuye a abaratar los procesos laborales, no sólo en segmentos de baja calificación sino también de alta calificación;

2. Desplazamiento. Los migrantes son utilizados para reemplazar contingentes laborales posicionados en mejores condiciones salariales y sindicales, en virtud de que están dispuestos a ocuparse en condiciones de mayor explotación laboral y exclusión;

3. Suplemento. Debido al menor ritmo de crecimiento poblacional observado, complementan la fuerza laboral necesaria para mantener el ritmo de acumulación y crecimiento;

4. Reemplazo. A través de la estrategia de internacionalización de la producción y generación de cadenas globales de producción, se desplazan puestos laborales hacia países subdesarrollados o periféricos que disponen de abundante fuerza de trabajo barata, y 
5. Desvalorización. Al contribuir al abaratamiento, desplazamiento, suplemento y reemplazo laborales, aunado al hecho de que están inmersos en actividades productoras de bienes salarios y el servicio doméstico, contribuyen a la desvalorización general de la fuerza de trabajo en el marco global de la reestructuración capitalista.

Tesis 3: Los migrantes contribuyen a dinamizar la producción y el consumo de la economía receptora

El foco de atención sobre la relación migración y desarrollo está ubicado en los impactos económicos de las remesas en el país de origen, ya sea a nivel macroeconómico, medido por los efectos en la balanza de pagos; a nivel meso, a través de los aportaciones a las regiones y comunidades, o a nivel micro, mediante la aportación de recursos para la subsistencia de las familias. Sin tomar en cuenta, por ahora, la validez de esa perspectiva, lo cierto es que la relación es más compleja y va más allá de los efectos unidireccionales en el país de origen.

De entrada, es importante considerar que la existencia de un vasto sector de migrantes mexicanos que viven y trabajan en Estados Unidos contribuye de manera directa a la dinamización de la producción y el consumo de ese país. En términos porcentuales, la contribución de los migrantes mexicanos al Producto Interno Bruto (Рів) de Estados Unidos prácticamente se duplicó en los últimos 14 años, al pasar de 2.3 a 3.8\%. Este último porcentaje representó para 2008 una contribución directa al PIB estadounidense de 531.6 mil millones de dólares, cifra equivalente al 57\% del PiB mexicano. Asimismo, vale la pena destacar que entre 1994 y 2008, el piB de Estados Unidos creció en términos reales 4,148 miles de millones de dólares (a precios de 2008); a este incremento los mexicanos aportaron 312 mil millones de dólares, lo que representa el 7.5\% de ese incremento.

\section{GRÁFICA 1}

Contribución porcentual de los migrantes mexicanos al PIB de Estados Unidos, 1994-2008

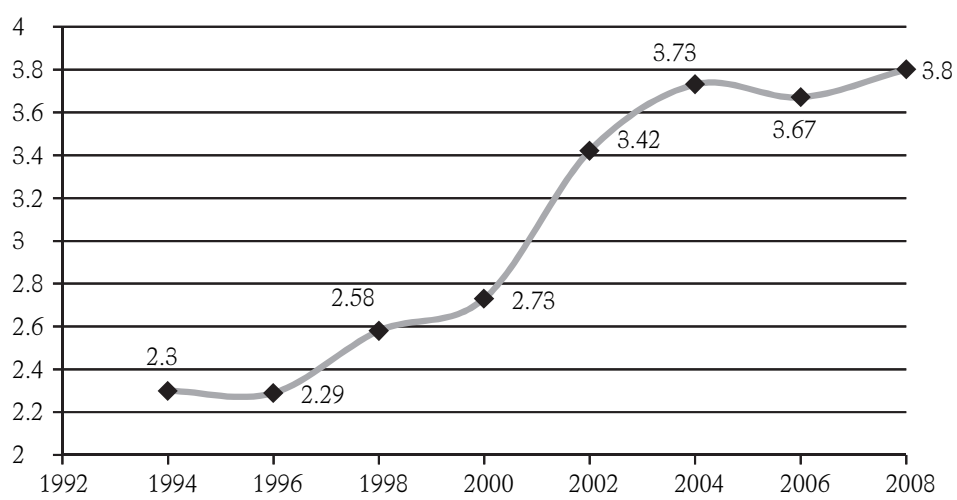

Fuente: Datos tomados de Canales (2009). 
El aporte que realizan los migrantes mexicanos a la economía de Estados Unidos tiene también un significativo impacto en la dinamización del mercado interno de ese país, no obstante que en conjunto perciben los niveles de ingreso más bajos, mediante el ejercicio de su capacidad de consumo. En efecto, los migrantes mexicanos coadyuvaron, de manera directa, con 400 mil millones de dólares a la dinámica del mercado interno estadounidense en 2008.

Más aún, entre 1994 y 2008, el consumo de Estados Unidos creció en términos reales 3,228 miles de millones de dólares (a precios de 2008). Para que este incremento fuese posible, los mexicanos aportaron 241 mil millones de dólares, lo cual representa el $7.4 \%$.

\section{GRÁFICA 2}

Contribución de los migrantes mexicanos al PIB y al consumo de Estados Unidos, 1994-2008

(Miles de millones de dólares a precios de 2008)

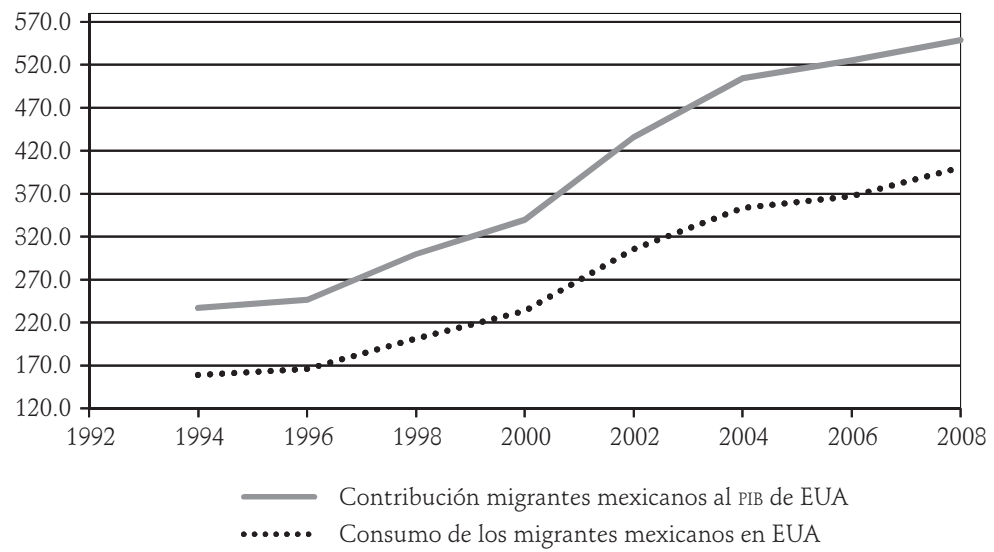

Fuente: Cálculo propios con base en Canales (2009) y Current Population Survey, Suplemento de Marzo, 1994-2008.

Para 2008, los migrantes mexicanos representaron cerca del 5\% de la población ocupada en Estados Unidos y su derrama salarial fue de alrededor de 217 mil millones de dólares anuales, que equivalen al 2.9\% de la derrama salarial estadounidense. De este ingreso, enviaron a México cerca del 12\% por concepto de remesas.

Como conclusión preliminar, podemos asentar la idea de que, no obstante las condiciones adversas en las que se desempeñan, los migrantes realizan importantes contribuciones a la dinámica de acumulación del país receptor:

1. La inclusión de la mayoría de inmigrantes depara la superexplotación laboral. Al estar inmersos en condiciones laborales adversas y de extrema vulnerabilidad en términos de intensidad, extensión de jornada laboral y baja remuneración, los migrantes están expuestos a riesgos laborales, exposición a enfermedades, inseguridad 
laboral, es decir, a un desgaste prematuro de sus capacidades laborales y a un deterioro de su calidad de vida.

2. El consumo en el umbral de subsistencia. El hecho de que los migrantes forzosos estén posicionados en las peores condiciones laborales y detenten los niveles más bajos de ingreso, los orilla a destinar la mayor cantidad de sus ingresos a sufragar los gastos necesarios para garantizar su propia subsistencia, muchas veces recurriendo al uso de créditos. Una de las expresiones más recurrentes es el consumo precario, debido a que reciben remuneraciones que apenas si alcanzan a cubrir los mínimos de subsistencia. Esto sin tomar en cuenta que una fracción de sus ingresos salariales está destinada al envío de dinero para sus dependientes económicos en sus lugares de origen.

Tesis 4: Los migrantes contribuyen al financiamiento de los sistemas fiscal $y$ de seguridad social del país receptor, pese a estar inmersos en condiciones de exclusión social y ostentar una ciudadanía precaria

Es común escuchar en el discurso dominante sobre migración y desarrollo la idea de que los migrantes son una carga fiscal y social para las naciones receptoras. Sin embargo dicho argumento no encuentra sustento al considerar el aporte que este grupo de la población realiza al erario público y al sistema de seguridad social del país de destino. Esto sin considerar los procesos de exclusión social a que frecuentemente se ven sometidos estos sectores de la población en virtud de su estatus indocumentado.

En el caso de los migrantes mexicanos residentes en Estados Unidos, la evidencia empírica contradice de manera contundente los argumentos antes esgrimidos y por el contrario dan muestras de que este grupo poblacional aportó al fondo fiscal estadounidense 52,800 millones de dólares por concepto de impuestos directos al trabajo y de impuestos indirectos vía consumo en 2008.7 Esta cantidad poco más que duplica al monto total de remesas enviado a México.

Lo paradójico de esta significativa contribución es que se realiza en un contexto de amplia vulnerabilidad económica y social por parte de los migrantes mexicanos, ya que en su mayoría se trata de trabajadores indocumentados que no tienen acceso a un amplio conjunto de servicios públicos y asistenciales disponibles para el resto de la población. Según estimaciones de Passel (2006), en 1990 el $46.5 \%$ de los inmigrantes mexicanos era indocumentado; en $2000,52.2 \%$, y en $2005,56.4 \%$.

Asociado a esta condición, los migrantes mexicanos ocupados carecen de una amplia gama de servicios sociales: la gran mayoría no tiene acceso al esquema de seguridad social ni a los programas de asistencia pública. El grueso de los migrantes mexicanos asalariados ocupan el escalón más bajo en la percepción de ingresos y presentan los mayores índices de pobreza. De acuerdo a la CPS (2008), 2.9 millo-

7 Los datos provienen de Current Population Survey y del esquema de impuestos aplicados bajo la U.S. Tax Law de los años 1992 al 2008. 
nes de migrantes mexicanos residentes en Estados Unidos, 1 de cada 4, son pobres. El acceso a los servicios de salud es limitado: 3 de cada 4 migrantes mexicanos ocupados no tiene acceso a un seguro de salud. Asimismo, no obstante hay una creciente selectividad en el proceso migratorio, los niveles educativos de los mexicanos siguen siendo relativamente bajos, en comparación con migrantes de otras nacionalidades y con la misma población de origen mexicano nacida en Estados Unidos: 6 de cada 10 cuentan con menos de 12 años de escolaridad.

\section{GRÁFICA 3}

Pago de impuestos por salario y consumo de los migrantes mexicanos en Estados Unidos, 1994-2008

(Millones de dólares)

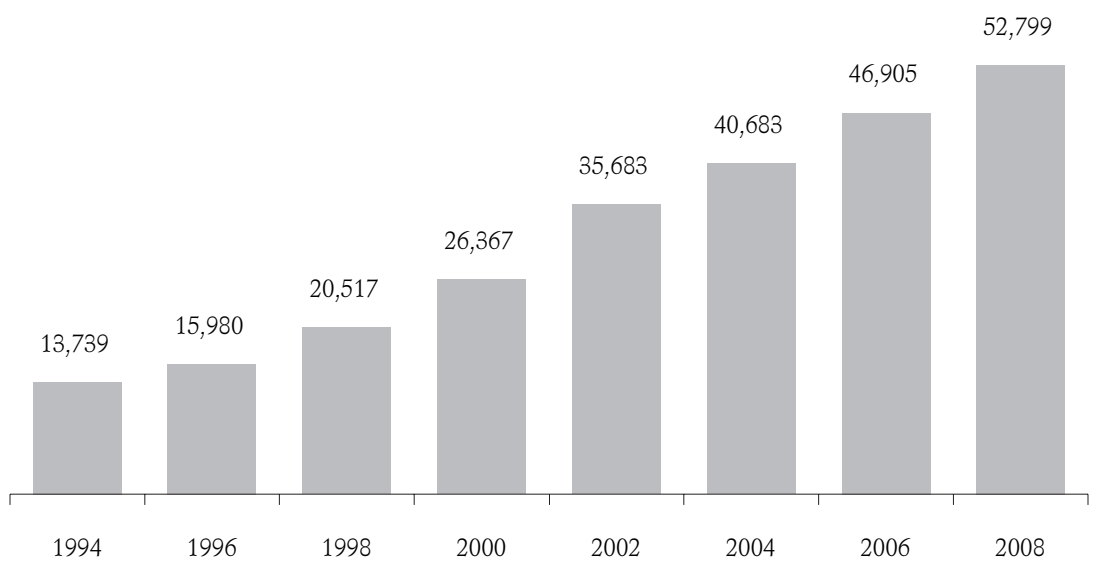

Fuente: Cálculo propios con base en Current Population Survey, Suplemento de Marzo, 1994-2008.

TABLA 3

Migrantes mexicanos ocupados en Estados Unidos y su carencia de seguro de salud, 1994-2008

\begin{tabular}{|l|c|c|}
\hline & 1994 & 2008 \\
\hline Migrantes ocupados & 3'638,809 & 7'494,003 \\
\hline Porcentaje sin Seguro de Salud & 72.3 & 74.7 \\
\hline
\end{tabular}

Fuente: Cálculos propios con base en Current Population Survey, Suplemento de Marzo, 1994-2008.

La inclusión laboral acompañada de exclusión social es la vía de participación para la mayoría de los mexicanos en Estados Unidos, y acusa, cuando menos, tres procesos adversos:

1. Contención a la movilidad social. Si a la precarización laboral y exclusión social le sumamos el compromiso familiar adquirido de enviar una fracción de su ingreso 
(vía remesas), se puede advertir que para los migrantes la capacidad de consumo se mina al igual que las posibilidades de ascenso social.

2. Estigmatización del migrante como mercancía humana. El migrante es reducido a su mínima expresión, como fuerza de trabajo barata, a la cual hay que explotar al máximo con el mínimo gasto social y la mínima retribución laboral. Y, llegado el caso, desecharla.

3. Subsidio al Estado. Los inmigrantes, además de estar sujetos a condiciones de superexplotación, financian al Estado sin recibir en contrapartida una dotación equivalente de servicios públicos, prestaciones y remuneraciones óptimas. En lugar de ello, son estigmatizados, criminalizados y segregados.

\section{TRANSFERENCIAS Y COSTOS DE LA MIGRACIÓN PARA LOS PAÍSES DE ORIGEN}

Desde la visión dominante sobre migración y desarrollo, que enfatiza un lado del problema, se plantea que los migrantes contribuyen mediante el envío de remesas a la formación del llamado capital humano, una expresión que encubre el propósito de reducir a la persona humana a su condición de recurso disponible para la explotación laboral. Desde ciertas posiciones se arguye que los migrantes demandan servicios educativos en los lugares de residencia que significan costos adicionales al Estado. Sin embargo, la evidencia demuestra que la migración trae consigo una forma de transferencia que aparece invisible para la mayoría de los analistas: los costos de preparación educativa y de formación de fuerza de trabajo en general son transferidos en el proceso migratorio, lo que representa ahorros importantes para la economía receptora.

La noción de transferencia bajo el espectro del desarrollo desigual significa que un país dominante extrae recursos de países o regiones sometidos política, económica o culturalmente. Estos recursos pueden ser económicos, culturales, poblacionales o naturales. Por ejemplo, excedente económico y personas. En este último caso, se trata, preponderantemente, de fuerza de trabajo barata cuyos costos de formación y reproducción corrieron a cargo del país emisor y ni un solo dólar al país receptor, lo cual significa un jugoso negocio para este último. Desde esta óptica, la migración forzada, más allá de sus causas de origen, se presenta como una forma de expoliación que se suma a otros tantos mecanismos de despojo y explotación que a la postre obran en perjuicio de las posibilidades de acumulación en las localidades, regiones y países de origen.

\section{Tesis 5: El proceso migratorio propicia importantes transferencias} de recursos económicos por concepto de formación educativa $y$ reproducción social de la fuerza de trabajo

El proceso de inserción laboral de los migrantes al mercado de trabajo del país receptor significa una transferencia de recursos derivada de los costos de formación 
educativa y reproducción social. Estos costos representan la inversión que realizó el país de origen en su programa de educación y el gasto familiar y social para la subsistencia y bienestar de quienes emigran. Visto de otra manera, la inmigración laboral entraña un significativo ahorro en la formación de fuerza de trabajo para el país receptor. Por las asimetrías socioeconómicas, estos costos son bastante menores en los países periféricos a diferencia de los países receptores.

La transferencia por concepto de gasto educativo de los migrantes mexicanos entre 1994 y 2008 fue de 83 mil millones de dólares a precios de 2008, si consideramos el nivel educativo al momento en que los migrantes arribaron por vez primera a Estados Unidos y estimamos los costos por nivel educativo correspondientes al sistema de educación pública. ${ }^{8}$ Esta cifra equivale al $45 \%$ del total de remesas familiares acumuladas que se enviaron a México en el mismo periodo.

El ahorro de Estados Unidos derivado del hecho de no erogar inversión en la educación de los migrantes laborales mexicanos fue de 613 mil millones de dólares de 1994 a 2008 (a precios constantes de 2008). ${ }^{9}$ Si las remesas fuesen consideradas una especie de "fuga de recursos» para el país de inmigración, su monto acumulado para el mismo lapso representaría apenas el 30\% de los ahorros educativos, sin considerar la contribución económica consignada en las tesis 2 y 3.

Además del gasto educativo, la migración representa una transferencia de recursos por concepto de reproducción social, es decir, el costo de vida del migrante antes de su ingreso al país de destino. Vale la pena señalar que el financiamiento de este costo se conforma de distintas fuentes que van desde los recursos públicos destinados al bienestar social comunitario hasta los gastos familiares básicos para el sustento de quienes emigran, incluyendo gran parte de las remesas que contribuyen a la formación de la nueva fuerza de trabajo migrante.

Si tomamos en cuenta tan sólo el costo de la canasta básica patrimonial propuesta por Consejo Nacional de Evaluación de la Política de Desarrollo Social (Coneval) como expresión del costo de vida, entre 1994 y 2008 México transfirió a la economía estadounidense 257 mil millones de dólares a precios de 2008. Esto implica 1.4 veces el monto de las remesas acumuladas captadas en el mismo lapso.

Al sumar las transferencias de recursos por concepto de inversión educativa y costos de reproducción social en el periodo de referencia, México contribuyó con 340 mil millones de dólares a la dinámica socioeconómica de Estados Unidos. Esta cifra equivale a 1.8 veces el monto de remesas acumuladas captadas por México. En esta estimación no se considera la contribución al empleo, producción, consumo e impuestos (véase gráfica 4). Desde esta perspectiva, resulta claro

\footnotetext{
\& Para este cálculo se utilizó el gasto por nivel educativo que presenta el Informe sobre el panorama educativo de México 2008 del InEe y datos del Current Population Survey 1994-2008.

9 Este cálculo se efectuó utilizando el gasto por nivel educativo que presenta el National Center for Education, US Department of Education 2007 y se combinó con datos del Current Population Survey 1994-2008.
} 
que la sociedad mexicana está subsidiando a la economía estadounidense a través de la migración laboral.

\section{GRÁFICA 4}

Comparación del gasto de reproducción social de la fuerza de trabajo migrante mexicana en relación con el volumen de remesas recibidas (miles de millones de dólares)

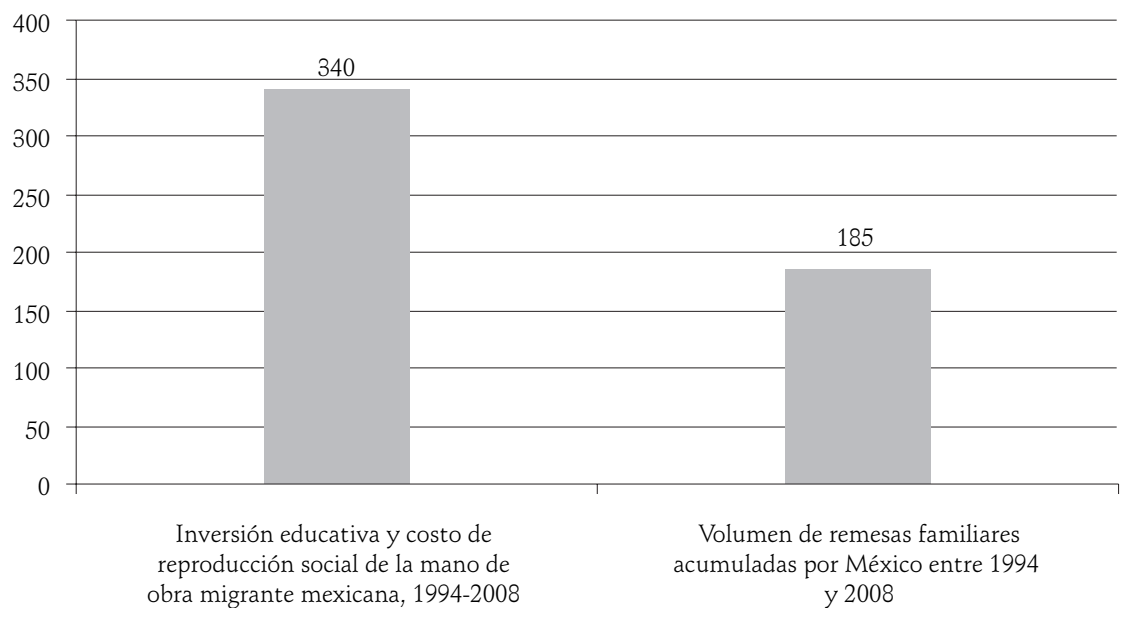

Fuente: Cálculos propios con datos de la Secretaría de Educación Pública de México (2008), del Current Population Survey (1994-2008) y del Consejo Nacional de Evaluación de la Política de Desarrollo Social de México (2008).

En términos de las relaciones de desarrollo desigual, podemos postular que la migración forzada está asociada a la profundización del subdesarrollo de la periferia, en contraposición a la promoción del desarrollo, por cuanto implica:

1. Transferencias de recursos humanos. Los países exportadores de fuerza de trabajo están transfiriendo su recurso más preciado, la gente. No sólo como fuente principal para la generación de riqueza, sino también como fundamento para la creación de lazos de sociabilidad, cultura y participación política abocados a la creación social de alternativas. Fenómenos como el despoblamiento, asociados a la migración forzada, son signos evidentes de la incapacidad para reproducir la vida en esas demarcaciones y de su entrega a países desarrollados, interesados en explotarlos intensamente.

2. Costos socioeconómicos. Más que un negocio redondo, donde todos ganan, la migración representa la transferencia de los costos de formación de la población migrante y otros costos colaterales, como el desmembramiento de familias, la vulnerabilidad epidemiológica, el despoblamiento, el abandono de actividades productivas, el alcoholismo y la drogadicción, la pobreza, la dependencia de las remesas, entre otros varios problemas socioeconómicos.

3. Beneficios al capital. El sector más beneficiado es el del capital que emplea a los inmigrantes en condiciones por demás ventajosas, y en términos más agregados, el Estado y la sociedad en general que ahorran recursos para la formación de nueva fuerza laboral, amén de que, como se argumento en las tesis 3 y 4 , su explo- 
tación acontece en condiciones de depresión salarial y exclusión social. Más aún, el propio proceso migratorio ha dado lugar a la proliferación de negocios muy lucrativos que acaban siendo aprovechados por grandes corporaciones transnacionales cuya base de operaciones se asienta en la economía receptora (Guarnizo, 2003)

\section{EL VERDADERO SIGNIFICADO DE LAS REMESAS}

La percepción de las remesas como una divisa fuerte que sostiene las cuentas externas, circulante monetario con efectos multiplicadores expansivos, recursos de calidad para detonar el desarrollo local, aportaciones filantrópicas para las comunidades desahuciadas o un río de oro que irriga los campos agrestes del tercer mundo para conducirlos por las aguas del progreso, son imágenes fetichizadas e ideologizadas del proceso migratorio. En ellas se pretende encarnar la representación del migrante como fuente de riqueza o capital, como persona emprendedora y exitosa, como una suerte de nuevo héroe del desarrollo que habrá de suplir o complementar las funciones del capital y el Estado. Ese discurso apologético encubre el tejido de relaciones enmarcadas en el desarrollo desigual que produce una abundante masa de trabajadores expulsados de su propio país y que ingresa a un mercado laboral excluyente y precarizado.

Tesis 6. Las remesas de los migrantes no compensan las transferencias y costos socioeconómicos que conlleva la migración forzada

Pese a que no existe ninguna constatación empírica ni fundamentación teórica, la idea de que las remesas de los migrantes se transforman en palancas o motores del desarrollo de los países de origen parecería incuestionable, si tomamos como referente el caudal de informes, artículos y discursos que, una y otra vez, reafirman ese nuevo mantra del desarrollo. El problema principal de esa formulación político-ideológica es que no toma en cuenta el contexto, como tampoco los procesos entrelazados ni los agentes involucrados. Y, en contrapartida, sobredimensiona bajo un halo de romanticismo la idea de que los migrantes se avienen en agentes o héroes del desarrollo, sin reparar en que la gran mayoría de ellos son trabajadores altamente explotados y excluidos que tiene ante sí el enorme reto de cubrir la subsistencia personal y familiar. Hacen caso omiso de las causas profundas de la migración (tesis 1), ocultan la contribución de los migrantes al país receptor (tesis 2, 3, 4 y 5) y sobredimensionan e idealizan las contribuciones que los migrantes realizan a sus depauperados lugares de origen mediante el envío de remesas, perdiendo de vista que estos lugares muestran, cada vez más, un paisaje desolador y opuesto a cualquier imagen de desarrollo: pueblos fantasmas, actividades productivas abandonadas, desarraigo y desesperanza. 
Además de preguntarnos qué son las remesas, la interrogante clave es cómo se producen. Al respecto, no debe perderse de vista que las remesas representan una parte de la remuneración salarial que envían los migrantes a sus dependientes económicos radicados en sus lugares de origen con el propósito de sufragar los gastos ordinarios para la subsistencia familiar (Márquez, 2007). La otra parte está destinada a sufragar la propia subsistencia y la de los dependientes económicos asentados en el país de destino. Por tanto, un problema central es develar las condiciones de vida y trabajo de los migrantes y sus dependientes económicos, en los lugares de origen y destino, para comprender la naturaleza y función de las remesas. A partir de esta visión de conjunto, las remesas configuran una forma de transferencia salarial desde los países desarrollados hacia los lugares exportadores de fuerza de trabajo. No obstante, bajo el desarrollo desigual, se puede advertir que son transferencias cuya cuantía las hace ver insignificantes si se las compara con las transferencias de recursos que le dan origen (véase tesis 1, 2, 3, 4 y 5). Esto quiere decir que las remesas de los migrantes están enmarcadas en modalidades de intercambio desigual dentro de la nueva división internacional del trabajo prohijada por la llamada globalización neoliberal, que en conjunto generan condiciones adversas a las posibilidades de crecimiento, acumulación y desarrollo de los países y lugares de origen.

Las remesas de los migrantes devienen de un salario que de origen ha sido reducido. Por lo mismo, se trata de una pseudosobresalario, es decir, de un salario en apariencia superior al que se percibe en el lugar de origen, pero menor al que captan otros contingentes laborales, en condiciones semejantes, en el país de destino. Es un salario que es fragmentado con el envío de remesas y que por lo general está por debajo del valor de la fuerza de trabajo, desde el punto de vista de las necesidades de subsistencia, reproducción y recreación prevalecientes en el país donde se trabaja; amén de que la fracción salarial enviada a los lugares de origen resulta insuficiente, pese al tipo de cambio asimétrico, para cubrir por sí solo la subsistencia familiar, y mucho menos para generar dinámicas de desarrollo. Por tanto, se trata de un salario generado en condiciones de superexplotación y exclusión social.

Uno de los casos más reveladores a escala internacional es el de México, considerado incluso como ejemplo de «buenas prácticas» en materia de migración y desarrollo. Entre 1994 y 2008, el país captó un monto acumulado de remesas familiares de 185 mil millones de dólares a precios de 2008. Más allá de la contribución de este flujo de divisas a la estabilidad macroeconómica del país, en tanto que representan la segunda fuente después del petróleo, y de su contribución a la estabilidad social al apoyar la subsistencia de alrededor de 5 millones de hogares mexicanos, al hacer el balance entre las formas de transferencia asociadas a la migración y la entrada de remesas -como quedó asentado en la tesis 5-, México pierde recursos netos que en estimaciones conservadoras prácticamente duplican sus percepciones bajo ese rubro. 
Más aún, las remesas tienen un impacto limitado en el desarrollo local y la disminución de la pobreza. Diversas encuestas han demostrado que las remesas se encuentran atomizadas y se canalizan preponderantemente a la subsistencia familiar, además de que los escasos recursos destinados a usos productivos están inscritos también en la lógica de la subsistencia. Si bien las remesas son un componente crucial de la estrategia de subsistencia de millones de hogares en México, sólo 1/3 de esos hogares logra una ligera mejoría que los ubicaría provisionalmente en los niveles bajos de la clase media, pero también en los umbrales de la pobreza. Visto de otra forma, sin la entrada de remesas la pobreza se incrementaría entre $1.5 \%$ (Rodríguez, 2007) y 1.9\% (Canales, 2008). Los pocos proyectos productivos financiados con remesas están desvinculados de estrategias de desarrollo local (Márquez, 2007).

A la luz de lo hasta aquí expuesto, podemos advertir lo siguiente:

1. La migración se asocia a diversos costos socioeconómicos para las familias, localidades y regiones de origen que no se compensan con la entrada de remesas. Estos costos son materiales y tangibles. Entre otros, se pueden señalar al despoblamiento, el abandono de actividades productivas y la dependencia de remesas en los niveles macro y micro.

2. Las remesas de los migrantes tienen una dinámica acorde a su naturaleza salarial. La insistencia en la idea de las remesas como fuente de desarrollo de los lugares de origen y del migrante como agente del desarrollo es una mistificación de la migración forzada, que concibe a las remesas de manera fetichizada y que además, haciendo tabla rasa de las condiciones de vida y trabajo, antepone una concepción extractiva del migrante como inagotable proveedor de recursos.

3. Las remesas representan un recurso marginal frente a la contribución de los migrantes a la sociedad receptora y a las formas de transferencia asociadas, y no se pueden vislumbrar como fuente del desarrollo para el país de origen. En el balance las remesas tienen como contrapartida nuevas formas de transferencia de recursos y forman parte de un engranaje que genera procesos de degradación social y económica. Ante la ausencia de un proyecto nacional, se genera una dependencia crítica de las remesas que prohíja fuertes transferencias de recursos materiales y humanos e inhibe posibilidades de desarrollo en el país emisor.

\section{CONCLUSIONES}

Para desmitificar la visión ideológica prevaleciente sobre migración y desarrollo es imprescindible realizar un esfuerzo que contribuya a repensar teórica, conceptual y empíricamente la relación entre desarrollo desigual y migración forzada. En esa ruta, el presente artículo permite arrojar las siguientes conclusiones:

1. La migración laboral forma parte del proceso de reestructuración capitalista. Los enfoques individualistas, microsociales y transnacionalistas resultan limitados para 
dar cuenta del complejo entramado estructural que subyace a las migraciones internacionales en la sociedad contemporánea, por cuanto tienden a aceptar acríticamente la formulación unidireccional y descontextualizada de la relación migración y desarrollo. En el contexto del desarrollo desigual y de la globalización neoliberal se reconfiguran las relaciones internacionales para dar paso a una nueva división internacional del trabajo que, entre otras cosas, expresa las relaciones de intercambio asimétrico que emergen de la abundante, flexible y desorganizada fuerza de trabajo barata a disposición del capital. En esta órbita, entra en escena la migración laboral canalizada hacia los países centrales como recurso estratégico para afrontar la competitividad internacional.

2. La migración contribuye preponderantemente al crecimiento económico del país receptor. Los migrantes son requeridos por el mercado laboral del país receptor con la finalidad de satisfacer su demanda laboral y abaratar sus procesos productivos, mediante el desplazamiento de trabajadores mejor posicionados y, en términos generales, la desvalorización de la fuerza de trabajo. En lugar de reconocer públicamente este aporte, los gobiernos de los países receptores difunden un discurso discriminatorio y criminalizador que concibe a los inmigrantes como una carga para la sociedad receptora y como un peligro para la seguridad interna. Al estigmatizar a esta fuerza de trabajo, perversamente se contribuye a su mayor desvalorización. Los países centrales son demandantes de amplios contingentes multinacionales de trabajadores calificados, poco calificados y no calificados, sean documentados o no. El Estado juega un papel importante en la regulación de los flujos migratorios de conformidad a los intereses de las clases dominantes y las corporaciones que representan. Al ocultar esta realidad, los migrantes se presentan, ante los ojos de la opinión pública de las sociedades receptoras, como culpables de muchos de los males que las aquejan: desmantelamiento del Estado de bienestar, achicamientos de las clases medias, desempleo y precarización laboral, etc.

3. La exportación de fuerza de trabajo entraña múltiples transferencias de excedentes y recursos materiales y humanos del país emisor al receptor que no son compensadas por el flujo de remesas. En la órbita del desarrollo desigual, los países periféricos se reinsertan a la dinámica de acumulación mundial en las peores condiciones. Más aún, los países que abrazan la ideología neoliberal sin reparos, entregan sus sectores estratégicos al capital foráneo y desmantelan sus limitados sistemas de bienestar social, al tiempo en que se ven orillados a incrementar la transferencia de excedentes, recursos naturales y humanos hacia el centro del sistema. Los países que se han especializado en la exportación de fuerza de trabajo, en apariencia están haciendo un negocio redondo pues depuran a su población considerada redundante, amortiguan el problema del desempleo estructural, aminoran los riesgos de conflicto social y edifican una nueva fuente de divisas representada por los recursos salariales enviados por los migrantes. Las remesas parecerían paliar el problema de la pobreza para los dependientes económicos de los migrantes, con lo cual se ofrece un "rostro humano» del modelo neoliberal, que con ello encuentra un puntal. Sin embargo, en el fondo, estos países están perdiendo recursos inapreciables para su propia sustentabilidad. En primer término, pierden la principal fuente de toda riqueza, la fuerza de trabajo. Además, transfieren junto con la mercancía humana 
de exportación los costos de formación educativa y los gastos familiares y sociales de reproducción. Esto sin tomar en cuenta que, por una parte, los migrantes están expuestos permanentemente a todo tipo de riesgos que ponen en peligro la vida misma, ya sea en toda la travesía migratoria como en su estancia en los lugares de destino, y, por otra parte, la migración está asociada a múltiples procesos de degradación social en el ámbito local, regional y nacional que no son subsanados con las remesas. Nos referimos a fenómenos como el despoblamiento, la dependencia de las remesas, el abandono productivo y la insustentabilidad social.

4. La integración asimétrica representa nuevas formas de intercambio desigual y abaratamiento laboral. El abaratamiento laboral ha sido una estrategia permanente de la reestructuración capitalista ensayada desde la década de los setenta. No han importado los costos humanos manifiestos en términos de pobreza, desempleo, hambre y violencia, todo ha estado centrado en el principio de maximizar los márgenes de ganancia para el capital, preponderantemente para el gran capital transnacional en mancuerna o alianza con una pequeña élite que controla el Estado nacional en los países emisores. En todo caso, lo importante para destacar es que, con la exportación de fuerza de trabajo, surgen dos nuevas modalidades de intercambio desigual, mucho más desventajosas para la periferia que aquella sustentada en el intercambio de productos primarios por productos industrializados que fuera ampliamente analizada y documentada por la Comisión Económica para América Latina y el Caribe (Cepal) y los teóricos de la dependencia a partir de los planteamientos de Emmanuel (1972). Por un lado, la exportación indirecta de fuerza de trabajo, derivada de la participación de los países periféricos en las cadenas globales de producción, significa la transferencia neta de ganancias al exterior. Se trata de una modalidad extrema de intercambio desigual que anula toda posibilidad de desarrollo y crecimiento económico en la periferia. No puede existir una modalidad más desventajosa y lacerante de intercambio desigual que aquella que implica la transferencia de la totalidad del excedente producido. Por otro lado, la exportación directa de fuerza de trabajo vía migración laboral implica no sólo la transferencia de los costos de formación y reproducción de la población forzada a desplazarse de sus lugares de origen, sino también la pérdida del recurso más importante para la acumulación de capital en el país emisor. La creciente incorporación de fuerza de trabajo altamente calificada de la periferia al centro agrava aún más esta problemática y compromete sobremanera las posibilidades de construir un sistema nacional de innovación sobre el que se finquen las perspectivas de desarrollo nacional del país emisor. Analizar estas nuevas modalidades de intercambio desigual plantea un importante desafío teórico, metodológico y empírico para avanzar en la concepción y caracterización del capitalismo contemporáneo y la problemática del desarrollo desigual. Los postulados que enarbolan las teorías del intercambio desigual, sustentados en las diferencias salariales que emergen de las trabas a la movilidad poblacional (que, en el lenguaje marxista, se conceptualizan como diferencias en las tasas de plusvalía), abren una importante veta analítica para avanzar en esta perspectiva.

5. La exportación de fuerza de trabajo no es ni puede llegar a convertirse per se en una avenida para el desarrollo. Queda demostrado que, contrariamente a la ideología neoli- 
beral de migración y desarrollo, la migración forzada, y su expresión estructurada de exportación de fuerza de trabajo barata, en lugar de conducir al desarrollo local, regional o nacional, es una expresión más del sometimiento de los países periféricos y de la profundización del subdesarrollo en el que se encuentran atrapados. El postulado de que los migrantes son los nuevos agentes del desarrollo es un principio emanado de la ideología neoliberal que oscurece la naturaleza del nexo migración-desarrollo y pretende achacar a los propios migrantes la responsabilidad de mejorar sus condiciones de vida y trabajo, sin tomar en cuenta las causas de fondo de la problemática y mucho menos proponiendo cambios estructurales, institucionales y políticos orientados a una transformación social sustantiva.

6. La vía para modificar el paradigma de migración forzada es colocar al desarrollo del país emisor en el centro y pugnar por nuevas formas de inserción a la economía mundial. Continuar excavando en la falsa idea de que la migración es fuente del desarrollo para los países de origen es brindar una carta de naturalización permanente al modelo neoliberal y a sus formas perversas de sobreexplotación laboral, extracción de excedentes y depredación ambiental. Es continuar poniendo en riesgo la subsistencia y la vida misma de millones de personas en el planeta con el afán de garantizar el incontenible proceso de concentración de poder, ganancia y riqueza en pocas manos. Es rendirse ante la idea autoimpuesta de que no hay alternativas y de que la actual trama de la globalización neoliberal es un desafío para imitar las políticas y modelo civilizatorio de los países centrales. Lo cual significa ocultar la voraz transferencia de recursos de la periferia al centro y los múltiples mecanismos asociados que boicotean el proceso de acumulación, crecimiento y desarrollo en esas anchas demarcaciones. Ante ese escenario truculento y plagado de contradicciones, se impone con mayor nitidez la necesidad de repensar el desarrollo de los países periféricos bajo nuevas orientaciones teóricas y políticas que contemplen transformaciones profundas en el entramado estructural, político e institucional, capaces de revertir las causas de la migración forzada y avanzar hacia una nueva arquitectura mundial que contemple la reducción de las desigualdades sociales, la disminución de las asimetrías entre países y la construcción de relaciones armónicas con el medio ambiente.

\section{REFERENCIAS}

American Community Survey (ACS) (2008), Washington, Bureau of Census.

Canales, Alejandro (2008), Vivir del Norte. Remesas, desarrollo y pobreza en México, México, Conapo, (Consejo Nacional de Población).

(2009), «Estimación del aporte de los inmigrantes mexicanos al PiB de Estados Unidos", Documento de trabajo, SIMDE.

Conapo (Consejo Nacional de Población) (2008), Migración internacional en www.conapo. gob.mx, accesado enero, 2009.

Consejo Nacional de Evaluación de la política de Desarrollo Social (Coneval) (2008), Informe de Evaluación de la Política de Desarrollo Social en México 2008, México, Coneval. 
Current Population Survey (CPS), suplemento de marzo, varios años, Washington, Bureau of Census.

Delgado Wise, Raúl y James Cypher (2007), «The Strategic Role of Mexican Labor Under NAFTA: Critical Perspectives on Current Economic Integration", The Annals of the American Academy of Political and Social Science, núm. 615, pp. 120-142.

y Humberto Márquez (2007), «The Resahaping of Mexican Labor Exports under NAFTA: Paradoxes and Challenges», International Migration Review, vol. 41, núm. 3 , pp. 656-679.

Emmanuel, Arghiri (1972), El intercambio desigual, México, Siglo XXI.

GerefFi, Gary (2001) «Las cadenas productivas como marco analítico para la globalización», Problemas de Desarrollo, vol. 32, núm. 125, pp. 10-37.

GuARnizo, L. (2003), «The economics of transnational living», International Migration Review, vol. 37, núm. 3, pp. 666-699.

Harvey, David (2003), The New Imperialism, Nueva York, Oxford University Press.

Instituto Nacional para la Evaluación de la Educación (inee) (2008), Panorama educativo de México. Indicadores del Sistema Educativo Nacional, México, INEE.

INEGI (2007), Encuesta Nacional de Ocupación y Empleo, Aguascalientes, Inegi.

Márouez, Humberto (2006), «El desarrollo participativo transnacional basado en las organizaciones de migrantes», Problemas del desarrollo, vol. 37, núm. 144, pp. 121-144.

(2007), «Controversias en el desarrollo económico local basado en las remesas de los migrantes», Análisis económico, vol. xxI, núm. 47, pp. 307-330.

(2008), «México en vilo: desmantelamiento de la soberanía laboral y dependencia de las remesas», Papeles de población, vol. 14, núm. 58, pp. 73-95.

PASSEL, Jeffrey (2006), «Size and Characteristics of the Unauthorized Migrant Population in the U.S.», Research report, March 7, Pew Hispanic Center, en http://pewhispanic. org/files/reports/61.pdf.

Robinson, William (2008), Latin American and Global Capitalism. A Critical Globalization Perspective, Baltimore, The Johns Hopkins University Press.

Rodríguez, Héctor (2007), «Remesas y pobreza en el contexto actual de la emigración mexicana hacia los Estados Unidos», en Agustín Escobar, Nación, Estado, comunidad: Consolidación y emergencia en la emigración mexicana, CIESAS (Centro de Investigaciones y Estudios Superiores en Antropología Social) y Editorial Antropofagia. 